Policy Research

Working Paper 1225

Intra-Sub-Saharan African Trade

The low levei of trade among Sub-Saharan African countries is actually slightly above what a traditional gravity model

Is It Too Little? predices

Faezeh Foroutan

I.ant Pritchett

The World Bank

Policy Research Department

Trade Policy Division

November 1993 
Policy Rlsharch Working Paltr 1225

\section{Summary findings}

Trade among Sub-Saharin Africinn countries is vers limited, This fact, plus other political and ecomomic considerations, has been used to motivate 1 growing number of reggional integration schemes.

Arhough many authors have shown thu inrri-subSaharan Atrican trade is limited, mone has yet anlied whether the level of intra-Sub soluran Atrican erade in higher or lower than one would experer, given at plausible model of the determmation of trate flews.

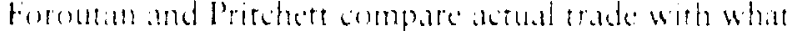
a tradirimal gravity modet would predier.

They timd that a growieg mindel predice the low level

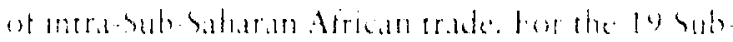

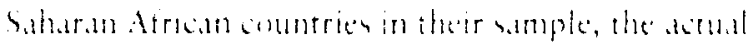
Sub Saharan Africun thare of importe plus exports wion

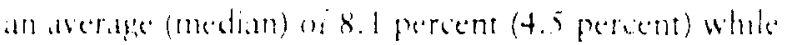

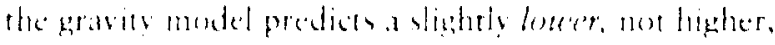
me.un (nection) of $7 . i$ percent $(4.5$ percent).

This paper - a product of the Trade Policy Division. Policy Rescarch Department - is part of a larger effore in the cepartment to study trade petterns in Sub-Saharan. Africa. Copicsos the paper are a ailable free from the World Bank,

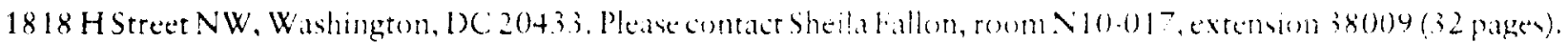
Novenber 1993

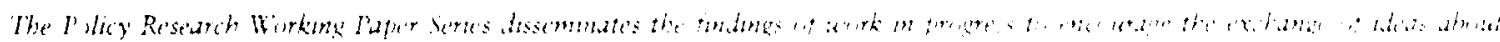

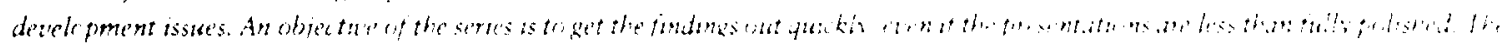

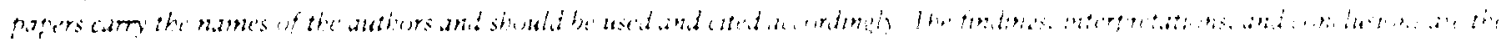

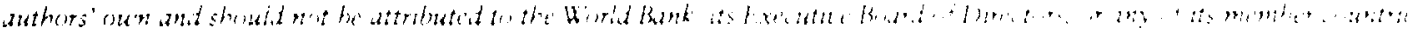




\title{
Intra-Sub-Saharan African Trade: Is It Too Little?
}

\author{
Faezeh Foroutan \\ The World Bank \\ and \\ Lant Pritchett \\ The World Bank
}

We wish to thank Jaime de Melo and two anonymous referees for their helpful comments on an earlier draft of this paper. 


\section{Intra-Sub-Saharan African Trade \\ Is it too I.ittle?}

\section{I) Introduction}

Official statistics suggest that trade among Sub-Saharan African" (SSA) countries as a whole, as well as among various regional groupings in SSA, is a small fraction of each country's total, and that share has remained roughly constant over the years (Table 1$)^{2}$. Many observers of African affairs believe this level of intra-SSA trade is "too small" and should be expanded further and a number of regional schemes have been initiated with that gual.

African countries' regional trade shares could be "too small" either normatively, in comparison to an optimal level, or empirically. Empirically, trade shares could be either absolutely small or small relative to expectations. While intra-SSA trade is absolutely small, we ask, is it smaller than expected? For whatever reason intra-SSA trade is judged to be too little, there have not been many attempts in the literature to quantify how little is little. In order to decide whether trade among the members of a regional grouping is "too little", some model for the determination of the volume of bilateral trade must be specified. We are not aware of any such model for the sub-region. As a resuit, there is a gap in the existing literature between the intuition that intra-SSA trade is too little and the empirical evidence to support the intuition. This paper is a partial attempt to fill this gap. It is a partial attempt for we look at the question strictly from a positive point of view. We ask a simple question: Compared to a sample of other countries with roughly similar economic characteristics, do

\footnotetext{
${ }^{1}$ Sub-Saharan Africa comprises all of the African continent except for Northern African countries (Algeria, Egypt, Libya, Morocco, and Tunisia) and South Africa, which is excluded because its bilateral trade is affected by obvious political factors.
}

2 We will return in section IV to a discussion of the unreliability of official trade statistics. 
SSA countries trade too little with each other? A traditional gravity model is employed to provide the answer. Contrary to popular belief, the gravity model produces no evidence that inter-SSA trade is below expectation. This conclusion does not of course contradict the claim that intra-SSA trade may be too little from a normative point of view, namely that it falls short of some welfare and growth enhancing level, although the burden of proof that higher trade among SSA countries would indeed lead to higher welfare and growth would fall upon the shoulders of the supporters of such a claim.

This paper has five sections. The first briefly reviews the arguments about the merits of regioual trade integration in SS.A and the previous empirical literature arguing that intra-SSA trade is low. The second introduces the gravity model of bilateral trade flows and reviews its merits. The third section estimates the parameters of a simple gravity model and uses these estimates to ask whether intra-SSA trade is systematically lower than the level predicted by the model. The fourth section discusses some additional implications of the model's estimates and addresses some limitations of the model -- in particular, the effect of existing regional arrangements on trade and the effect of unrecorded intra-SSA trade on our analysis. The final section discusses the interpretation of the positive results and the relationship between our positive finding and normative policy recommendations. 


\section{II) Regional Trade Integration: Background and Previous Literature}

Regional integration (RI), mostly understood as the integration of goods and factors markets through discriminatory trade arrangements, has been a persistently pursued goal by SSA countries in the past three decades. The creation of an African Common Market by .ne year 2000 represents the ultimate objective of numerous existing integration schemes ${ }^{3 /}$ in the African continent. RI, by enabling individual countries to overcome the barriers of small size and poor human and physical capital endowment, has been considered by many African politicians and scholars as a prerequisite for breaking away from the colonial pattern of trade, often characterized by heavy reliance on an undiversifier and vulnerable structure of exports, and for fostering economic growth.

The normative view of the desirability of increased trade among SSA countries is closely related to the literature in favor of increased South-South trade in general and to arguments in favor of regional economic integration SSA in particular". Increased trade within the various regional groupings and within the SSA as a whole has been considered an essential indicator of the success of the various integration schemes on both political and economic grounds. Politically, many African states have equated "increased intra-African trade with self-reliant policies required to break from the economically 'dependent' trading patterns established during the colonial period ${ }^{\text {mot. }}$

\footnotetext{
${ }^{3}$ For a summary of the principal characteristics of the most important regional groupings in SSA see T:ble 1 .

'For a critical -eview of this literature and evaluation of developing countries' experience with South-South trade arrangements see Greenaway and Milner (1990) and Langhammer and Hiemenez (1990).

${ }^{5}$ For a critical review of arguments in support of regional integration in SSA and evaluation of SSA countries' experience with regional integration see Foroutan (1992).

${ }^{6}$ Berg (1988), p. 13.
} 
Economically, increased intra-African trade is also a natural indicator of the extent of integration and of the achievement of the preconditions for realizing the theoretical advantages associated with greater integration. For example, if a theoretical advantage of integration consists in intra-regional product specialization to exploit szale economies", and/or to reduce the cost of achieving a specific level of industrial output for each member country", then greater product specialization would certainly be assuciated with greater intra-regional trade. Thus, the failed increase in intra-SSA trade is evidence of the failure of integration efforts in SSA".

As is widely known, intra-SSA trade flows are small in absolute magnitude. Total exports from SSA in 1988 vere $\$ 3.66$ bn.; by comparison, Brazilian exports were $\$ 8.7$ bn. to the US and $\$ 9.3$ bn. to the EC. Intra-SSA trade is also a small fraction of their total trade -- only $5.3 \%$ in 1988 , down from $5.7 \%$ in $1970^{10}$. However, to our knowledge only two recent studies attempt to quantify if actual trade is less than either potential or expected trade.

'See Corden (1972).

'See Johnson (1965) and Cooper and Massell (1965).

${ }^{9}$ Many proponents of RI in SSA remain silent on the fact that increased trade among countries adhering to a regional integration scheme does not necessarily indicate that the scheme itself is welfare enhancing for the welfare effect of such a scheme depends not only on how much trade has been created amung partner countries but also on how much trade has been diverted from the rest of the world. A prominent example is that of the Eastern European countries which were quite successful in increasing trade among themselves, but their distorted pattern of trade was almost surely welfare reducing. See fo example Havryly:hyn and Pritchett (1991).

${ }^{10}$ UNCTAD Handhnok of International Trade and Development Statistics, 1990. Exports from Developing Africa to Developing Africa. 
The first, Mansoor et al. (1989), argues for the existence of sizable unexploited potential trade within SSA. They define potential trade as " $" \mathrm{a}$ value of imports currently coming from the rest of the world for which at least one SSA country is making significant exports (at least one percent of its exports) to the rest of the world" (p.45). This potential trade was computed using UN COMTRADE 1983 trade flows at the four digit SITC level of disaggregation. Potential intra-regional trade for SSA as a whole was $\$ 4.5$ billion, 16 percent of the region's total exports for that year.

However, this calculation alone cannot suggest that intra.SSA trade is too small. One needs a model for the expected value of this "potential" trade. While une can perhaps define "potential" trade, as total within region intra-product-category trade, associating that with "unexploited potential" trade implicitly assumes that the expected, or even attainable, value of intra-product-category trade is zero. A vast literature on intra-industry trade shows there are sound reasons for the simultaneous import and export of similar goods even in the most successfully integrated regions. For eximple, intra-product-category trade for the USA and the $\mathrm{EC}^{111 /}$ in 1983 was equal to 22 and 14.5 percent of their non-oil imports respectirely, roughly the same as that for SSA. Given the complete (or nearly so) absence of barriers to trade in goods within the US and the EC, one would be hard pressed to identify this trade as "unexploited" regic.al trade potential or to argue that these levels

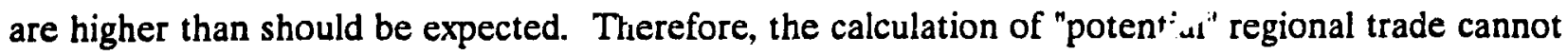
begin to address the question cî expected regional trade unless in addition to calculating potential trade, some reasonable notion of expected potential trade is also created.

\footnotetext{
"This is the current European Community minus Portugal and Spain.
} 
In the second study, Kourouma (1989) focuse on West Africa and employs a probabilistic model, first developed by Savage and Deutsch (1960), to compute the value of expected trade between any pair of countries. In Kourouma's model the expected value of trade flowing from country $i$ to country $j$ is derived from the share of $i$ in to s : " orld exports and the share of $j$ in total world imports. Roughly speaking, if the share of $i$ in total world exports is $p$ and the share of $j$ in total world imports (which is equal to total world exports) is $q$, the expected trade between $i$ and $j$ is approximately equal to $p$ times $q$ times the total value of world trade. Using this definition of expected trade, Kourouma constructs an index of the deviation of the actual trade $\left(T_{i j}\right)$ from the expected trade $\left(E_{i j}\right)$ between $i$ and $j$ as:

$$
R_{i j}=\left(T_{i j}-E_{i j}\right) / E_{i j}
$$

The ratio $R_{i j}$ can vary from minus one to plus infinity. A negative value of $R_{i j}$ means that actual trade between countries $i$ and $j$ fell short of the expected. A positive value indicates that trade between $i$ and $\mathrm{j}$ exceeds the expectations.

The calculation was made for thirteen Western African countries for two time periods, ; 972 77 and 1978-83. In seven of thirteen cases $R^{i j}$ was negative for both time periods, suggesting that for those countries intra-SSA trade was less than expected, while for the rest the evidence was ambiguous.

Kourouma's study makes an advance on simply comparing shares of trade by adjusting for relative sizes. For example, French imports from Belgium are only $9 \%$ of French imports, and so are an absolutely small share. However, Belgium's exports are only $3.4 \%$ of world exports. Thus the 
ratic of Belgium's share of French imports to Belgium's share of world imports is 2.6 , suggesting that French imports from Belgium are relatively large. However, this example makes it clear that this simple adjustment is far from adequate as a model for predicting trade flows, as factors that would explain why French imports from Belgium arc relatively high (e.g., proximity, a shared bordei, no trade barriers, a shared language) are excluded. We turn next to the gravity model, which incorporates these factors into a model f $\sim$ bilateral trade flows. 


\section{III) The Gravity Model}

The gravity model posits that the volume of trade bet een any two countries $i, j\left(T^{i}\right)$, is a function of each countiy's trade potential (TP, TPj) and their mutual trade attracticn (TA $\left.{ }^{i j}\right):^{12}$

$$
\text { 1) } T_{y}=f\left(T P_{1}, T P_{j}, T A_{y}\right)
$$

In orcer to implement the gravity model, we specify the factors that affect the trade potential of each sountry and the factors that affect the trade attraction between countries.

A country's absolute trade potential depends on its tota! economic size (GDP) and the trade intensity (the ratio of irade to GDP). A country's trade intensity is affected both by its geugraphic and economic characteristics ${ }^{13}$. The geographic determinants of trade intensity that we use fall into two classes: size and island. The greater a country's total area, the smaller the fraction of economic activity that is expected to cross borders. Whether or not a country is an island can also affect total trade, but the effect is ambiguous, as one would expect lack of land borders to reduce trade, but to the extent islands are poorly endowed with resources, this will require additional trade. Economic factors can also affect trade intensity, but are much more difficult to capture. We use the level of GDP per capita as a proxy for the level of econumic development.

12 The gravity model is so named because of the andlogy with gravitational force between two objects, that depends on the masses of the objects and $t_{i}$. Jistance.

13 Many applications of the gravity model substitute actual trade flows for trade potential specifying the model as:

$$
T_{i j}=f\left(T_{i}, T_{j}, T A_{i j}\right)
$$

where $\mathrm{T}$ is trade. Our model can be thought of as predicting trade as a function of trade potential and trade attractiveness simultaneously. 
The trade attraction between two partners is determined by the total cost of bilateral trade. Total cost includes transport costs, poiicy and political barriers to trade, as well as general "business environment" variables, such as sharing a common language. A key element of the traditional gravity model is the dual recoguition that transport costs are a major determinant of trade attractiveness and that the distance between two countries is a good proxy for transport custs ${ }^{14}$. Sharing a common border $w$ suld tend to increase trade flows, even for a given distance. The attractive...ss of trade between any two countries can also be enhanced by policy choices, such as the existence of preferential trade arrangements (e.g., the EEC) or discriminatory barriers (e.g., the USA and the: USSR). Finally, the trade attractiveness of any two countries can be influenced by cultural or historical factors. Cultural similarity can increase trade if the type of goods produced is similar. Sharing a common language can increase trade by facilitating communication. Additionally, historical ties (such as colonial relationships) can enhance the ties of transport and communication. Finally, two hypothesis exist on the effect of the difference between two countries' levels of per capita income. The Linuer $h_{j}$ pothesis is tha countries with similar living standards will share a broader range of goods to trade and hence trade, especially inter-industry trade, wil! be higher. On the other hand, GDP per capita differences are highly correlated with differences in factor endowments and hence smaller differences could reduce trade, especially comparative advantage driven intra-indust $y$ trade.

Summarizing our gravity model is of the form:

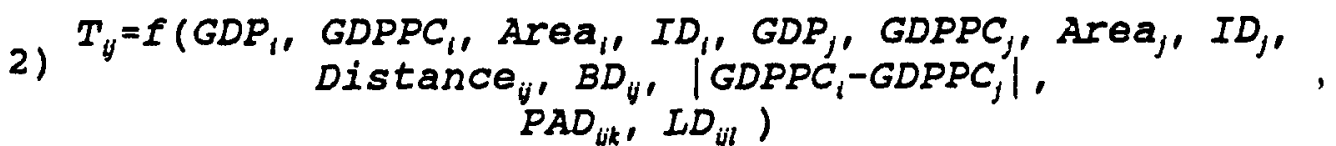

$$
\left.P A D_{i j k}, L D_{i j l}\right)
$$

14 Various improvements on the gravity model are premised on finding better proxies for transport cost than distance. Balassa and Noland, 1988, Geraci and Prewo, 1977. 
where GDPPC is GDP per capita, ID is a dumniy if $i$ is an island, BD is a dummy variable if $i$ and $\mathrm{j}$ share a border, PAD is a set of dummy variables for a set of $\mathrm{k}$ different preferential trade arrangements ( $=1$ if both $i$ and $i$ are members of the particular arrangement), LD is a set of dummy variables if countries share a similar language $(=1 \mathrm{f} i, j \text { share ianguage })^{15 /}$. A brief data appendix describes the data and the sources used.

The gravity model has been widely and successfully used in the empirical literature on international trade ${ }^{16}$. Aitken (1973) used the model to estimate the effect of the EEC on trade flows, finding that the trade effects of the EC grew over time as policy integration proceeded. Havrylyshyn and Pritchett (1991) used this model to show that trade between Eastern Europe and Western Europe is much less than forecast by the model, which has been consistent with the massive realignment of trade underway subsequent to the demise of the CMEA. Thoumi (1989) used a similar approach to study the trade effects of regional trade preference arrangements in Latin America. Srivasta and Green (1986) u\& a gravity model to show the importance of the existence of political variables.

Although equation 2 is unwieldy, the basic logic is straightforward. The model allows other factors to play a role in determining bilateral flows so that, even though Belgium's ( $\$ 192 \mathrm{bn})$ and Mexico's ( $\$ 236 \mathrm{bn}$ ) GDPs are roughly the same, the trade between Belgium and France will be predicted (correctly) to be much larger than trade between Mexico and France.

15 We allow the affect of sharing a language to vary across languages and allow the effect of various trade agreements to vary across agreements, as not all are expected to have the same impact.

${ }^{16}$ Deardoff (1984), in his review of empirical work on international trade, says "In spite of their dubious theoretical heritage, granting models have been extremely successful empirically". 
Equation 2 will $t a$ estimated and used to determine whether intra-SSA trade is less than expected, given the determinants. We use two approaches. The first approach estimates the gravity model without the SSA countries in the sample and uses the estimated coefficients from this model to predict intra-SSA trade. These predictions are then compared with actual flows. The second includes the SSA countries in the estimation sample and introduces dummy variables to test for differences in intra-SSA trade. 
IV) Estimation and Empirical Results

Table 2 presents the results of estimation of equation 2 in natural logarithms ${ }^{17}$. Since we are interested in countries whose trade patterns are determined similarly to those of the African countries (that is, whose gravity model parameters are a priori similar), the non-African reporter countries are limited to those countries with GDP per capita less than USS 3,000. In addition, countries whose total trade in 1980 was less than USS 300 million are excluded. This criterion limited the number of reporter countries to thirty-four non-African and nineteen SSA countries. For each reporter country (i) the trade with each of ninety-five partners (j) is included for a total of 3,230 nonAfrican, or 5,035 total observations. We use only non-fuel trade (total trade less SITC 3), as the determinants of bilateral flows of fuel trade (primarily petroleum and coal) are likely different than other trade flows. The model is estimated for imports and exports separately, for two reasoris. First, bilateral import patterns may be determined differently than export patterns. Second, and importantly in the SSA case, using both imports and exports attenuates the problem of unrecorded trade (see below) as one reporter's recorded imports are a partners's exports and vice versa.

Before reporting the results, we must discuss one econometric complication in estimating equation 2. Since the value of trade flows cannot be negative, the value of the dependent variable is censored at zero, and OLS in this case produces inconsistent estimates. This problem has generally been ignored in the empirical literature. However, under certain conditions, the OLS bias is linear in the inverse of the proportion of the sample not at zero (Greene, 1981). For low income countries the fraction of bilateral trade observations at zero is .3 or higher, implying that OLS estimates will

17 The model was estimated in logs to make the estimates less sensitive to extreme observations to provide elasticities that are easy to interpret and compare with those in the literature. 
be biased towards zero by roughly $40 \%$. This is consistent with our findings, as the maximum likelihood (tobit) estimate of the coefficient on distance was generally higher that the OLS estimate by a third or more.

The basic idea behind censored dependent variable models is that instead of the conditional expectation of $\mathrm{y}$ given $\mathrm{x}$ being linear, the model is:

$$
\begin{array}{ll}
E(Y \mid X)=\beta^{\prime} X & \text { if } \beta^{\prime} X+\epsilon>0 \\
E(Y \mid X)=0 & \text { if } \beta^{\prime} X+\epsilon \leq 0
\end{array}
$$

The predicted value of $\mathbf{y}$ conditional on $\mathbf{x}$ is zero if the predicted actual value is less than zero, and is the linear function of $\mathrm{X}$ otherwise. We used the tobit estimates that correct for this censoring bias by estimating using the maximum likelihood function:

$$
\begin{gathered}
\ln L=-\frac{n_{1}}{2}\left(\ln (2 \pi)+\ln \left(\sigma^{2}\right)\right)-\frac{1}{2} \sigma^{2} \sum_{1}\left(T_{i j}-\beta^{\prime} X_{i j}\right)^{2}+ \\
\sum_{0}\left[1-\Phi\left[\frac{\beta^{\prime} X_{i j}}{\sigma}\right]\right]
\end{gathered}
$$

where the summation subscript 1 indicates a sum $c$ rer the observations with positive trade $\left(T_{i y}>0\right)$ and subscript 0 indicates observations at the truncation point $\left(T_{1 y}=0\right)$ and $X_{1 y}$ is the matrix of trade determinants. This estimation form gives the intuition that the positive 
observations are used to estimate the relation of value of trade to determinants, given trade is positive, while the observations at zero are used to estimate the probability trade is positive.

As usual, the gravity model's empirical performance is good. An appropriately calculated ${ }^{12}$ $\mathrm{R}$-squared for the non-African sample is .646 for imports and .578 for exports. These are quite high values for cross-sectional regression and suggest that the gravity model does a reasonable job of predicting the pattern of trade flows. Nearly all of the variables have the expected sign and most are statistically significant ${ }^{19 /}$. As expected, trade volume increases significantly with a common border and falls off quite sharply with distance. Trade increases with total output, roughly one for one. The larger the reporter's country's area and the higher the GDP per capita of the reporter the lower the trade potential, although for partner countries there is no significant effect of GDP per capita. A shared language increases trade significantly. Similarly, all of the included preference arrangements show a large positive effect.

We will use this model to examine African trade in two ways. Say we partition the data between African and non-African countries:

$$
\left[\begin{array}{c}
T^{\text {Afr }} \\
T^{\text {Non-Afr }}
\end{array}\right]=\left[\begin{array}{cc}
X^{\text {Afr }} & 0 \\
0 & X^{\text {Non-Afr }}
\end{array}\right] *\left[\begin{array}{c}
\beta^{\text {Afz }} \\
\beta^{\text {Non-Afr }}
\end{array}\right]+\left[\begin{array}{c}
\epsilon^{\text {Afr }} \\
\epsilon^{\text {Non-Afr }}
\end{array}\right]
$$

\footnotetext{
${ }^{18}$ In a non-linear model such as the Tobit, the strict linear decomposition of total errors is not possible. The R-squared reported is 1-SSE/SST, where SSE is $\varsigma(y-\varphi) 2$ where $\varphi=\Phi(x * \beta / \sigma), \Phi($.$) is the cumulative standard normal distribution$ function.
}

19 The standard errors reported are the heteroskedascity consistent standard errors of White (1981). 
Our first method predicis the African trade flows using the coefficients from the low income, nonAfrican country sample and the African determinants, i.e. $\hat{T}^{\lambda f s}=X^{\lambda f x} * \beta^{\text {pan-Afr }}$. The second method tests whether intra-African trade is different by introducing shift variables that would allow African trade to be lower or more responsive to distance within Africa, holding other coefficients constant. 


\section{IV.A) Simulated Intra-SSA Trade}

The first method of testing the hypothesis that intra-SSA trade is too low is to compare actual intra-SSA trade to the trade predicted for the sub-region by combining estimates of the gravity model coefficients that exclude data on SSA trade with SSA data for the independent variables. The estimates from columns 2 and 4 of Table 2 are used to simulate the predicted pattern of bilateral trade for each of the nineteen SSA countries in the sample. The values of the independent variables (GDP, distance, etc.) are used to predict the bilateral flow with each of the 95 partners ${ }^{20}$, which are then used to calculate the shares of trade. The predicted bilateral trade shares for SSA assume that trade flows in the sub-region were determined exactly like for the other low income countries determined by our estimated gravity model. Table 3 compares the actual import and export shares of SSA countries in the sample with their predicted trade. If intra-SSA trade were low for reasons particular to the sub-region, then the model would predict greater intra-regional trade than actually observed. This is not the case.

Actual imports from other SSA countries are higher than predicted imports for nine of the nineteen countries (about half). For all nineteen countries, the mean (median) share of actual imports is $3.5 \%(1.8 \%)$ versus the predicted mean (median) values of $3.6 \%(2.4 \%)^{21}$. On average

${ }^{\infty}$ The usual $\mathrm{x}^{*}$ Beta prediction predicts only the value of trade, given that it is larger than zero. In the tobit case the predictions are $\Phi\left(\frac{x * \beta}{\partial}\right) *(x * \beta)$, where $\Phi($.$) is the cumulative$ standard normal distribution, the probability that trade is greater than zero, times its predicted value, conditional on being non-zero.

${ }^{21}$ We report the mean and median since some of the countries have very high actual shares and low predicted values. 
3.5\% of these countries' imports come from other African countries, wher sas the gravity model predicts an only slightly higher value, $3.6 \%$.

The share of exports going to other SSA countries is higher than predicted in eleven of the nineteen cases. The mean (median) actual trade share of $4.6 \%(2.7 \%)$ is somewhat higher than the predicted mean (median) of $3.9 \%$ (2.1\%). According to these estimates, African countries export more than expected to other African countries.

These results suggest that the low share of intra-SSA trade is more than fully accounted for by the fact that those SSA countries which are close to other SSA (and hence are their natural trade partners) are also countries that are very poor and quite small and hence have very little trade potential. All SSA non-oil exports were only about $1 \%$ of total world non-oil exports in 1988 and so the crudest share calculations would suggest that if SSA countries traded in proportion to total trade, the share of a given SSA country going to SSA would only be $1 \%$. The gravity model increases that prediction to account for proximity, common borders, etc, and raises that prediction to $3.5 \%$, on average. After accounting for trade potential and trade attraction, discrepancies between Africa's predicted intra regional trade and actual trade are very small. 


\section{IV.B) Direct Estimates of SSA Trade}

The second method for testing whether intra-SSA trade is lower than expected is to include variables that directly capture SSA specific effects in the determination of bilateral trade. We include four dummy variables for the region. These variables indicate statistically if SSA trade patterns differ from the other countries in the sample. The four dummy variables are:

African ${ }^{i}$, , $=1$ if both the reporter and the partner are in SSA.

African, " distance ${ }^{\mathrm{ij}}$, an interaction of distance and the dummy variable African ${ }^{\mathrm{ij}}$.

African, = 1 if the reporter country is in SSA;

African oili, = 1 if the reporter is an SSA oil exporter;

The dummy when both partner and reporter are in SSA is the critical variable. If it is negative this indicates that, holding other factors constant, African countries trade less with each other than similar countries do with their neighbors. The coefficient on the second dummy variable will be negative if distance is a greater barrier to trade amongst SSA countries than other countries with similar characteristics, as has been suggested due to poor infrastructure. The coefficients on the final two variables indicate if the trade of SSA countries (or SSA oil countries) with all partners is higher or lower than trade of non-African countries with similar characteristics. If the coefficient is negative, then SSA trade is too low in the sense that African colntries trade less in total than other countries, again ceteris paribus.

Columns 1 (for imports) and 3 (for exports) of Table 2 report the results when the SSA countries and the African dummy variables are included. The coefficient on the dummy variable African $^{\mathrm{i}}$ in the import regression is negative, implying that total non-oil imports of the African 
countries are lower than those of other economically similar countries. This is consistent with the general perception that total SSA imports are affected by restrictive trade policies.

The variable of primary interest, the dummy variable for intra-SSA trade (African ${ }^{i j}$ ), is positive but statistically insignificant. Thus, if anything, intra-SSA imports are actually higher than expected using the c nventional gravity model. There is no evidence of any differential bias against intra-SSA trade. The export results tell a similar, stronger story. The dummy variable for intra-SSA exports is strongly (.84) and significantly (t-stat 2.22 ) positive. From the gravity model, there is simply no evidence that SSA countries trade less with each other than would be expected given their low trade potential. The estimates indicate the opposite. In spite of the fact that the share of intra-SSA trade is low in absolute terms, it is actually higher than expected on the basis of the underlying determinants. ${ }^{2 /}$

As mentioned earlier, it has often been argued that poor communications and transportation infrastructure linking SSA countries has been an important impediment to trade within the subregion. The lack of adequate infrastructure suggests that distance would be a greater barrier to trade between SSA countries than between other countries. In order to test this conjecture, the interactive dummy variable African ${ }^{\mathrm{ij} *}$ distance $^{\mathrm{ij}}$ is included in the estimated equation. This variable takes the value of the log of distance if both reporter and partner are in SSA. If distance were a greater inhibiting factor to trade for SSA than for other countries, the coefficient on this variable should be negative, indicating a sterper fall of trade with respect to distance for trade within SSA. The results in Table 2 indicated that while the point estimate in both the import and the export regressions are negative,

\footnotetext{
${ }^{2}$ If the regression equations that includes SSA countries are run in levels as opposed to natural logarithms, the coefficient on the dummy variable African ${ }^{\mathrm{ij}}$ is positive but insignificant in both the import and the export equations. These results broadly agree with those in the text.
} 
they are both practically and statistically insignificant. The coefficient estimate for imports (exports) of $-.06(-.13)$ is about one-fourth (one-half) its standard error $.225(.242)$. A standard error confidence interval around the point estimates (from .28 to $.16,-.37$ to .11 ) includes numbers equal in magnitude but of opposite sign. The gravity model gives little evidence that in fact distance is a greater barrier to intra-SSA trade than it is for other countries. This result goes against the apparently common feeling that the poor quantity and quality of communications and transport infrastructure between SSA countries is a major obstacle to intra-SSA trade. However, if the optimal investment in infrastructural links is related to trade potential, this result may suggest that the infrastructure may be no worse than expected, g:ven the low trade potential.

Other interesting points emerge from the regression results. First, as suggested by other studies, some regional arrangements appear to have increased trade amongst their members. The dummy variables for regional trade arrangements outside SSA, namely the Association of Southeast Asian Nations (ASEAN), the Latir American Free Trade Area (LAFTA), and the Central American Common Market (CACM) are all positive and significant. If we include among the preferential agreement variables three regional arrangements for SSA countries (CEAO, ECOWAS, and UDEAC), only CEAO appears to have positively and significantly affected intra-sub-regional trade. The coefficient on the dummy variable for ECOWAS is positive in the import equation and negative in the export equation but insignificant in both cases. The coefficient on the dummy variable for UDEAC is negative throughout and insignificant. This result is fully compatible with the pattern of intra-group trade reported in Table 1. The data indicate that between 1970, when CEAO was not yet created, and 1975, two years after CEAO was formed, intra-CEAO trade share doubles but remains stagnant thereafter. Intra-ECOWAS and intra-UDEAC trade patterns, on the other hand, appear to be unrelated to the formation of the two groupings in 1975 and 1976, respectively. Whatever the 
impact of the regional groupings on the trade pattern of their nember states, it must be once more stressed that the fact that intra-regional trade is high does not necessarily imply that the preferential trade arrangements were beneficial as the trade may be diverted, rather than created trade.

Second, no variables were included for colonial status, but a dummy variable was included that indicated if the reporter was an ACP (African-Caribbean-Pacific) country and the partner an EC country, to account for Lome preferences. This effect was strong and significant for both exports from, and more intriguingly, imports into the ACP countries, where EC's imports generally receive no formal preference. The estimated effect on imports is smaller than exports. This suggests that the Lomé preferences have been successful in increasing ACP exports to the EC. The Lome preference on imports may reveal any number of things: either tied aid, the effect of colonial relationships, or perhaps that prices are higher into Africa (Yeats, 1990b) given that the dependent variable is the dollar value of trade. The strong effect of the language variables also suggests that historical/cultural/colonial ties have a significant impact on the pattern of trade. 


\section{IV.C) Limitations of the Empirical Results}

As with all empirical work, there are limitations to t.،e present study. We will discuss two classes of limitations: data related and conceptual.

First, official trade statistics for Africa are extremely defective. They ignore a great deal of trans-border trade which routinely takes place amor, neighboring countries ${ }^{24}$. It is estimated that for some countries the unrecorded trans-border trade (UTT) may be as high if not higher than recorded trade ${ }^{24}$. Because of the magnitude of the UTT in Africa, it is believed that the use of official statistics may seriously under-estimate the true amount of intra-SSA trade. Moreover, for reasons that range trom the degree of competence of customs officiais to under- or over-invoicing and the use of artificial prices in evaluating the flow of tiade, whatever trade is detected, is recorded with a great deal of error. For all these reasons, there often exists a large discrepancy between reporter and partner recorded trade flows in SSA. For example. Yeats (1990a) shows that the average discrepancy between matched export and import values for thirty-five SSA countries in 1982-83 was more than sixty percent. However, the existence of UTT likely strengthens our conclusions.

The existence of UTT flows should lead to a serious under-estimation of the true magnitude of intra-SSA trade relative to non-SSA trade. This creates a bias to find trade too low, not too high or about right. First, in recorded border trade, although UTT is large, it is known that most of this trade takes place in goods of foreign origin and/or goods of domestic origin but ultimately destined

\footnotetext{
${ }^{23}$ On the importance, institutions and consequences of unrecorded trans-border tracie in SSA see Azam (1990), Barad (1990), and Deardorff and Stolper (1990).

See Barad, op. cit.
} 
to foreign markets and as such does not qualify as true intra-SSA trade. For example, Barad (1990, p. 104) states that "Muci of the trade in manufactures appears to involve products originating from outside the African region Locally produced agricultural products, minerals, and wild animal products (skins, ivory) enter UTT because of export restrictions or unfavorable government-fixed producer prices. Exchange rate policies, domestic industry protection, government subsidies, and tariffs are among the other determinants influencing the direction of UTT flows. Such flows are likely wherever divergent government policies in nearby states result in significant differential between local market prices. The size of UTT flows will vary according to the profits realized by moving these goods across the border". However, to the extent that official siatistics do underestimate the true amount of intraSSA trade, our conclusions are unaffected or rather strengthened, for if the present results show that official trade is no lower than expected, then the ac ual trade among SSA countries must a fortiori be above the expected when the expectations are formea on the basis of data on countries with less porous frontiers.

Finally, the discrepancy between reporter and partner data also leaves our results unaffected since we implicitly use both reporter and partner data by using imports and exports separately. Therefore, the results are not affected by asymmetric reporting errors. The discrepancies between reported imports and cxports for African countries do not drive our results as they are consistent for both flows.

The second data limitation of our results is that the sample includes only nineteen SSA countries. This is not a serious limitation for two reasons. First, all of the economically larger SSA countries that account for the bulk of intra-regional trade are represented. The column in table 3 shows the share of trade with all SSA and with our sample. Rarely is more than $1 \%$ of trade missed 
by excluding the smaller African countries. Second, unless the bias against trade with the sub-region is larger for economically smaller couniries, there is no reason to believe that the resuits would be different for the other countries.

The major conceptual limitation of the present paper is related to the model used to predict trade flows. The gravity model is not a well specified economic model because the equation explaining the trade volume is not derived from the optimizing behavior of economic agents, although some theoretical rationalizations do exist (Anderson, 1979 and Bergstand, 1989). However, there are two defenses. First, the model in fact performs well, producing empirically plausible results here and in other literature.

More importantly, a basic message of this paper is that some model needs to be used to form judgements about whether a given level of intra-regional trade is high or low. In much of the existing literature on intra-regional trade, the model implicitly used is naive, as shares of regional trade are compared directly across regions. There is always some interest in the statement that intra-SSA trade is $5.3 \%$ of SSA trade while intra-EC trade is $60 \%$ of all EC trade. However, the more interesting question is whether intra-SSA trade is lower than expected. Only if trade is lower than expected do obstacles need to be invoked to explain why it is low. The latter question requires a model on the basis of which the expectations are formed. While the gravity model has its limitations as a model of bilateral trade volume, it is certainly preferable to forming conditional expectations naively on the basis of crude shares. Perhaps a different model of bilateral trade volume with greater sophistication and empirical credibility would show that intra-SSA trade is low relative to expectations formed under that model. Until then, the conclusions with our gravity model, however suspect, are the best quantitative judgement available. 
VI) Conclusion

It has been argued that trade among SSA countries is also too small and obstacles are frequently mentioned to explain why: insufficient or non-existing transportation and communications networks within the sub-region ${ }^{2 s}$, itself a direct consequence of centuries of colonial domination; the existence of a multiplicity of non-convertible currencies for countries (outside the CFA franc zone $)^{20 /}$; extreme ethnic, cultural and linguistic diversity; and very high political instability ${ }^{27}$.

This paper asks a simple question and gets a simple answer. We ask, is the observed small proportion of intra-SSA trade less than one would expect? Using the gravity model of bilateral trade volumes as the basis for predicting trade flows we can answer, no. The low degree of intra-SSA trade is completely explained by the low degree of trade potential amongst the countries, primarily because of their low level of GDP. There is no evidence that intra-SSA trade flows are differentially low either because of policy or infrastructural weakness.

Of course, by asking a simple question, we forego answering more complicated ones. For example, what would be the potential trade among SSA countries had there been complete liberalization of trade flows among them and how does this potential compare to the actual? Or, by how much would the potential trade itself increase if some of the more structural barriers to intraSSA trade were removed? Or more complicated still, are efforts at increasing intra-regional trade

${ }^{25}$ See for example Diouf (1990).

${ }^{20}$ See for example Frimpong-Ansah (1990).

${ }^{27}$ All of these factors could naturally be also thought of as having contributed :c a gricatci auu lesser extent to the failure of integration efforts in SSA. 
in SSA a good thing? This paper can't and doesn't say. However it does contribute to the debate by showing that the low degree of intra-SSA trade is not the result of factors that work differentially against such trade. Increasing intra-SSA trade is not just a matter of removing discriminatory distortions or biases in infrastructure. It require positive action, such as providing differential incentives to intra-regional trade. However, providing differential incentives that raise trade above the "natural" level must clearly first be justified on the ground that it is welfare improving.

In our view, the fundamental explanation for the failure of various RI schemes in SSA to increase the flow of trade among the SSA countries is to be linked to the inability and/or unwillingness of these countries to carry out the preferential trade liberalization measures that represent the prerequisite for trade creation among integrating markets. Failed preferential trade liberalization among the majority of SSA regional groupings is itself a function of several factors. These include fiscal revenue constraint, the uneven distribution of costs and benefits of integration among participating countries to various schemes, the associated difficulty in devising proper compensation schemes from the gainers to the losers, and the inward-looking, import-substituting economic philosophies that have guided the policy action of the majority of African governments ${ }^{22}$.

\footnotetext{
is Sce torouitun, ôp. cit.
} 
Table 1

GENERAL CHARACTERISTICS OP REGIONAL GROUPINGS IN SSA" 1989 UNLESS OTHERWISE INDICATED

\begin{tabular}{|c|c|c|c|c|c|c|c|c|c|c|c|c|c|}
\hline \multirow[t]{2}{*}{$\begin{array}{l}\text { Narre of Regional } \\
\text { Jrouping }\end{array}$} & \multirow[t]{2}{*}{$\begin{array}{l}\text { Date } \\
\text { Crented }\end{array}$} & \multirow[t]{2}{*}{$\begin{array}{l}\text { Number of } \\
\text { Meambera }\end{array}$} & \multirow[t]{2}{*}{$\begin{array}{l}\text { Total Population } \\
\text { (millions) }\end{array}$} & \multirow[t]{2}{*}{$\begin{array}{c}\text { Total } \\
\text { GNP } \\
\text { (bil.\$) }\end{array}$} & \multirow[t]{2}{*}{$\begin{array}{l}\text { Per capitu GNP } \\
\text { (US \$) }\end{array}$} & \multirow[t]{2}{*}{$\begin{array}{l}\text { Degrte of opennew } \\
((X+M) / G N P)\end{array}$} & \multicolumn{5}{|c|}{$\begin{array}{l}\text { Share of Inera-group Expon Trade in Tocel } \\
\text { Exports }\end{array}$} & \multicolumn{2}{|c|}{$\begin{array}{c}\text { Trade with SSA } \\
\text { A } x \text { of total } \\
\text { exports }\end{array}$} \\
\hline & & & & & & & 1970 & 1975 & 1980 & 1985 & 1990 & 1980 & 1990 \\
\hline \multicolumn{14}{|l|}{ WEST IFRICA } \\
\hline ECOWAS & 1975 & 16 & 195 & 64 & 326 & so & 2.9 & 4.0 & 3.5 & 5.3 & 5.7 & 3.6 & 6.4 \\
\hline CEAD & 1973 & 7 & so & 24 & 476 & 46 & 6.3 & 12.7 & 8.9 & 8.7 & 10.5 & 13.2 & 15.0 \\
\hline MRT & 1980 & 3 & 12 & 4 & 355 & 46 & 0.2 & 0.4 & 0.5 & 0.4 & 0.1 & 0.9 & 2.9 \\
\hline \multicolumn{14}{|l|}{ CENTAAL AFRICA } \\
\hline UDEAC & 1976 & 6 & 24 & 19 & 806 & 42 & 4.8 & 2.7 & 1.6 & 1.5 & 3.0 & 2.1 & 5.9 \\
\hline CEPIL & 1982 & 3 & 47 & 12 & 260 & 28 & 0.4 & 0.3 & 0.1 & 0.8 & 0.2 & 4.1 & 7.6 \\
\hline \multicolumn{14}{|l|}{$\begin{array}{l}\text { EAST AND } \\
\text { SOUTH } \\
\text { SRN AFRICA }\end{array}$} \\
\hline PTA & 1981 & 18 & 212 & 58 & 274 & 40 & 8.0 & 9.3 & 7.6 & 5.5 & 5.9 & 8.4 & 7.6 \\
\hline SADX:C & 1980 & 10 & 80 & 25 & 311 & S5 & 2.6 & 3.7 & 2.1 & 3.9 & 4.8 & 3.5 & 6.3 \\
\hline SACIR' & 1910 & 5 & 39 & 89 & 2294 & 54 & n.a & n.e. & n.a. & n.e. & n.e. & n.a. & n.a. \\
\hline TOTAL SSA & & 47 & 480 & 162 & 340 & 43 & & & & & & 2.8 & 6.9 \\
\hline
\end{tabular}

If SS، is uniformly defined to exclude South Africa.

2' Dall for SADCC and SACU exclude Namibis.

ECOW.AS = Economic Community of Weatem African States, includes: CEAO and MRU membern plus Cape Vende, Gambia, Ghans, Guinea Bizenu, Nigeria and Togo.

CEAO = Communaute Economique de L'Afrique de L'Ouea, includes: Benin, Burkinu Faso, Core d'lvoire, Mali, Mouritanie, Niger and Seacgel.

MRU = Mano River Union, includes: Guines, Liberia, Siern Leone.

UDEAC: = Union Duanière et Economique de L'Afrique Cenirale, includes: Cameroon, Central African Republic, Chad, Congo, Equatorial Guinea and Gabon.

CEPGL = Commenaule Economique des Payı des Grando Lacs, includes: Burundi, Rwanda and Zaire.

PTA = Preferential Trade Area for Eastern and Southern African States, includes: Angohn, Bunundi, Comomo, Djibouti, Ehhiopia, Kenya, Lemotho, Malawi, Mnuritiun, Mozambique, Rwanda, Somalie, Sudan, Swariland,

Tan zania, Uganda, Zambia, Zimbabwe.

SADCC = Southem African Development Coondination Conference, includea: Angole, Botawana, Leaotho, Melawi, Mozambique, Namibin, Swaziland, Tanzenia, Zambin, Zimbebwe

SACU : Southem African Cuntoms Union, includen: Botowam, Lewotho, Namibin, South Africa, and Swaziland 
Table 2

Maximum Likelihood Entimales of the Tobit Gravity Model for Countries with GDP per capile < 3,000 as Reporters

\begin{tabular}{|c|c|c|c|c|}
\hline & & & & \\
\hline & $w /$ African & w/o African & w/ African & w/o Africen \\
\hline African dummie. & & & & \\
\hline African' $(=1)$ & $-.34(.08)^{* *}$ & & $.08(.103)$ & \\
\hline African oil $\exp (=1)$ & $-.06(.132)$ & & $-1.07(.165)^{\infty}$ & \\
\hline African $n^{2 j}(=1)$ & $.60(.319)$ & & $.78(.318)^{\star}$ & \\
\hline African * dian" & $-0.07(.196)$ & & $-.11(.196)$ & \\
\hline Proximity & & & & \\
\hline Distance' & $-1.66(.07)^{* 4}$ & $-1.75(.077)^{\cdots \bullet}$ & $-1.69(.074)^{\infty}$ & $-1.65(.080)^{* *}$ \\
\hline Border $(=1)$ & $.68(.23)^{\cdots \cdots}$ & $.54(.308)$ & $.89(.23)^{\infty}$ & $.89(.309)^{\infty+}$ \\
\hline Reporter & & & & \\
\hline GDP & $.82(.031)^{\star *}$ & $.88(.036)^{44}$ & $1.31(.040)^{* *}$ & $1.53(.050)^{\infty}$ \\
\hline GDPPC & $.14(.048)^{* *}$ & $.098(.057)$ & $-.38(.051)^{* *}$ & $-.63(.058) \cdots$ \\
\hline Area & $-.18(.028)^{\star \bullet}$ & $-.18(.033)^{* 4}$ & $-.44(.037)^{* 4}$ & $-.53(.047)^{\infty}$ \\
\hline Laland $(=1)$ & $-.01(.083)$ & $.06(.045)$ & $.20(.095)^{\star}$ & $.22(.112)^{\circ}$ \\
\hline Partner & & & & \\
\hline GDP & $1.34(.025)^{\star \star *}$ & $1.28(.023)^{* *}$ & $.97(.029)^{* *}$ & $.94(.036)^{\infty}$ \\
\hline GDPPC & $-.08(.038)^{\star}$ & $-.009(.045)$ & $.08(.042)$ & $.07(.048)$ \\
\hline Areej & $-.28(.018)^{\infty}$ & $-.214(.023)^{n \bullet}$ & $-.19(.021)^{* 0}$ & $-.19(.025)^{\infty 1 *}$ \\
\hline Leland $(=1)$ & $.33(.081)^{* *}$ & $.505(.098) \cdots$ & $-.08(.089)$ & $-.06(.108)$ \\
\hline | GDPPC - GDPPC | & $-.11(.05)^{\bullet}$ &. $.029(.066)$ & $-.11(.058)$ & $.03(.069)$ \\
\hline Preferential & & & & \\
\hline ASEAN & $.81(.278)^{* *}$ & $.621(.291)^{\star}$ & $1.45(.36)^{* *}$ & $1.32(.37)^{\circ \bullet}$ \\
\hline LAFTA & $.94(.25)^{* 4}$ & $.92(.263)^{* *}$ & $\therefore .59(.23)^{4 *}$ & $1.68(.24)^{\cdots+}$ \\
\hline $\mathrm{CACM}$ & $3.26(.33)^{* *}$ & $3.31(.37)^{* *}$ & $3.37(.29)^{* *}$ & $3.46(.26)^{\star *}$ \\
\hline Lome & $.94(.173)^{\star \star}$ & $.26(.208)$ & $1.66(.157)^{* *}$ & $1.20(.53)^{*}$ \\
\hline Language & & & & \\
\hline Engliah & $.49(.138)^{\infty+}$ & $.73(.202)$ & $.32(.144)^{\star}$ & $.15(.213)$ \\
\hline French & $1.26(.183)^{\infty}$ & $.53(.55)$ & $1.42(.202)^{* *}$ & $1.47(.66)^{*}$ \\
\hline Spanish & $.62(.155)^{\star *}$ & $.67(.162)^{*}$ & $.43(.173)^{* *}$ & $.72(.18)^{*}$ \\
\hline congtant & $1.59(.201)^{\star *}$ & $1.19(.24)^{\star \bullet}$ & 1.96 & $1.67(.27)^{\bullet \bullet}$ \\
\hline " Counuriea (obva) & $54(5,130)$ & $34(3,230)$ & $53(5,035)$ & $33(3,135)$ \\
\hline s.e. & 1.88 & 1.91 & $2 . \infty 0$ & 2.00 \\
\hline Preudo $R^{2}$ & .630 & .646 & .555 & .578 \\
\hline
\end{tabular}

Note: Standard errora in parenthesis, ${ }^{* *}(*)$ - significant at the $1 \%(5 x)$ level. 
Tabie 3

Compariwon of Actual and Gravity Model Predicted Value of Intra-SSA

Trade Sharea for Nineceen SSA Countriea; Average Values for 1980-82

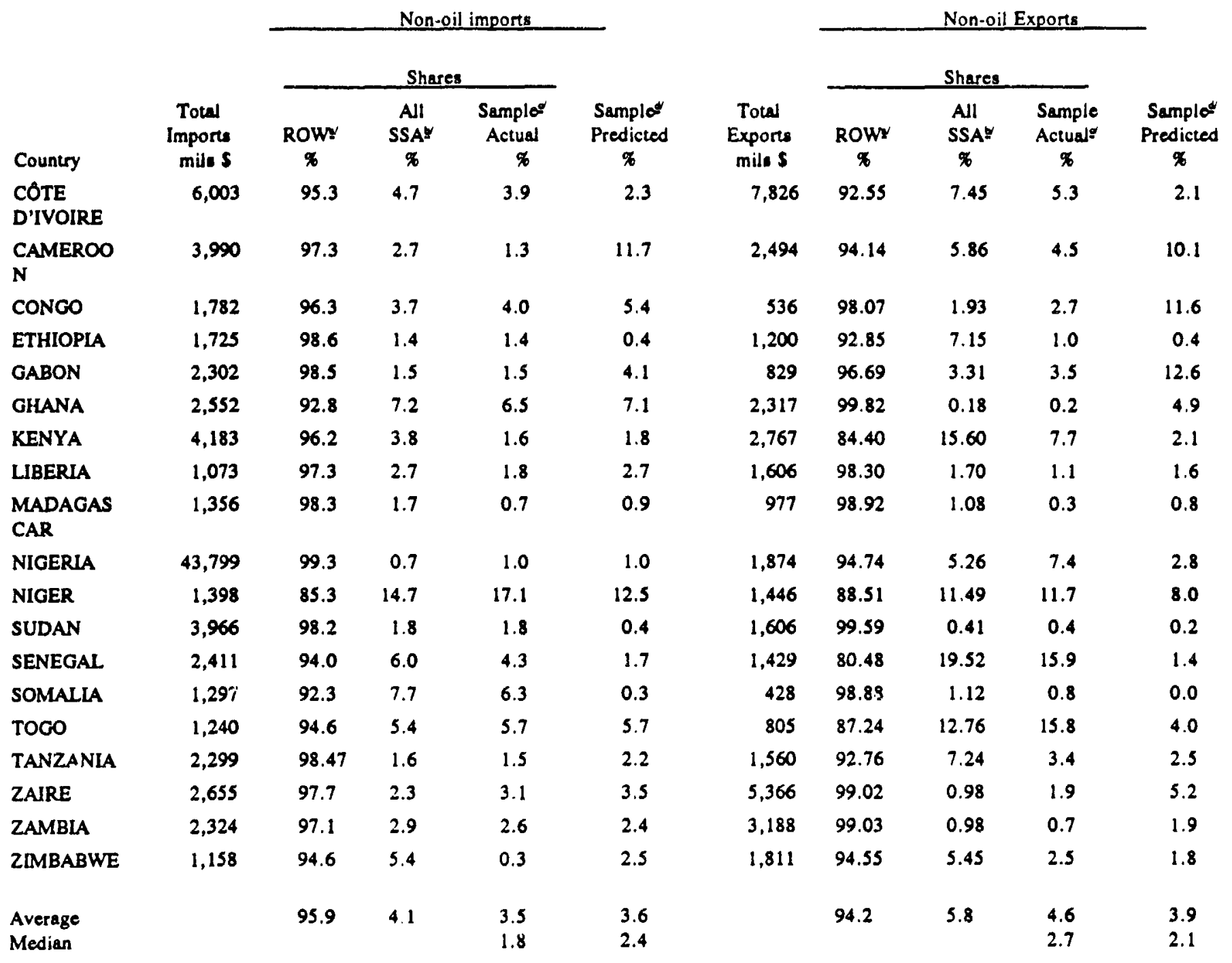

ROW = Reat of the World.

100 - ROW Share

Trade with the SSA countries in the cample as a percentage of trade with all partner countries in the sample.

Predicted share of trade with the SSA countries in the sample; all trade data from COMTRADE. 
Imports, Exports

$\mathbf{M i j}, \mathbf{X i j}$

\section{Geegraphy}

Distanceij - The straightline distance between economic center of gravity of the respective countries, from Linneman (1966).

Borderi, $\quad=1$ if countries $i j$ share a border, 0 otherwise.

\section{Economic activity}

GDPi

GDPPCi - GDP per capita of the reporter from World Bank Allas.

Sizei - The land area of the reporter in '000 square kilometers.

Islandi $\quad=1$ if reporter is an island.

GDPj - Total GDP in USS of the partner country from World Bank Atlas.

GDPPCj - GDP per capita of the partner from World Bank Atlas.

Sizei - The land area of the partner in '000 square kilometers.

Islandi $\quad-\quad=1$ if partner is an island.

Linder - The absolute value of the difference in per capita GDP between the source and partner, from Summers and Heston (1988).

\section{Trade preference arrangements}

$D$ ij - This is a dummy variable $=1$ if both countries are members of any type of preferential trading agreement. The arrangements included are: ASEAN, CACM, CEAO, ECOWAS, EEC, EFTA, LAFTA, UDEAC, and Lomé preferences.

Cultural

L ij - The only cultural factor considered is whether or not the countries share the same language, a very crude, but easily calculated proxy. Dummy variables were included for English, French, and Spanish. 


\section{Bibliography}

Aitken, N.D., 1973, "The Effect of the EEC and EFTA on European Trade: A Temporal Cross-Section Analysis," American Economic Review, v. 63, \#5, pp. 881-92.

Azam, J.P., 1990, "Informal Integration Through Parallel Markets for Goods and Foreign Exchange", in The Long Term Perspective Study of Sub-Saharan Africa, vol. 4, the World Bank, Washington, D.C.

Anderson, J., 1979, "A Theoretical Foundation for the Gravity Model," American Economic Review, v. 63 (December), pp. 881-892.

Balassa, B. and M. Noland, 1988, Japan in the World Economy, Institute for International Economics.

Barad, R., 1990, "Unrecorded Transborder Trade and its Implications for Regional Economic Integration, in The Long Term Perspective Study of Sub-Saharan Africa, op. cit.

Berg, Elliot, et al., 1988, "Regional and Economic Development in Sub-Saharan Africa", a study prepared for USAID, Alexandria, Virginia.

Bergstand, J., 1989, "The Generalized Gravity Equation, Monopolistic Competition, and the Factorproportions Theory in International Trade", Review of Economics and Statistics, March, pp. 143153.

Corden, W.M., 1972, "Economies of Scale and Customs Union Theory", Journal of Political Economy, v. $80,465-75$.

Cooper, C.A. and B.F. Massell, 1965, "Towards a General Theory of Customs Union for Developing Countries", Journal of Political Economy, v. 73, August, pp. 461-75.

Deardorff, A.V., 1984, "Testing Trade Theories and Predicting Trade Flows," in R.W. Jones and P.B. Kenen (eds): Handbook of International Economics, v. I, Elsevier Science, Amsterdam.

Deardorff, A.V. and W.F. Stolper, 1990, "Effects of Smuggling under African Conditions: A Factual, Institutional and Analytic Discussion", Weltwirtschaftliches, v. 126, \#1, pp. 116-141.

Diouf, M., 1990, "Evaluation of West African Experiment with Economic Integration", in The Long Term Perspective Study of Sub-Saharan Africa, op. cit.

Foroutan, F., 1992, "Economic Integration in Sub-Saharan Africa: Experience and Prospects", Policy Research Working Paper, WPS 992, the World Bank, Washington, D.C.

Frimpong-Ansah, J.H., 1990, "The Prospects for Monetary Union in ECOWAS", in The Long Term Perspective Study, op. cit.

Geraci, V. and W. Prewo, 1977, "Bilateral Trade Flows and 1 ransport Costs, "Review of Economic and Statistics, February, pp. 67-74. 
Greenaway, D. and C. Milner, 1990, "South-South Trade: Theory, Evidence and Policy", The Wurld Bank Research Observer, v. 5, \#1, pp.47-68.

Greene, W., 1981, "On the Asymptotic Bias of the OLS Estimator of the Tobit Model," Econometrica, v. $49, \# 2$, pp. 505-73.

Johnson, Harry G., 1965, "The Economic Theory of Protectionism, Tariff Bargaining, and the Formation of Customs Unions", Journal of Political Economy, 73, August, pp. 327-45.

Havrylyshyn, O. and L. Pritchett, 1991, "Direction of Trade After Transition in East Europe: Predictions from a Gravity Model", PRE working paper 748, the World Bank, Washington, D.C.

Kourouma, M., 1989, International Trade Flows and Economic Interdependence in the West African Market, Ph.D. dissertation, Rensselaer Polytechnic Institute, Troy, N.Y.

Langhammer, R.J. and Hiemenez, U., 1990, "Regional Integration Among Developing Countries: Survey of Past Performance and Agenda for Future Policy Action", UNDP-World Bank Trade Expansion Program, the World Bank, Washington, D.C.

Linneman, H., 1966, An Econometric Study of International Trade Flows, Noth Holland, Amsterdam.

Manscior, Ali et at., 1989, "Intra-Regional Trade in Sub-Saharan Africa", Report no. 7685, the World Bank, Washington, D.C.

Savage, I.R. and K.W. Deutsch, 1960, "A Statistical Model of the Gross Analysis of Transaction Flows", Econometrica, v. 28, \#3 (July), pp. 551-572.

Srivasta and Green, 1986, "Determinants of Bilateral Trade Flows," Journal of Business, v. 59, \#4, pp. 623-640.

Summers, R. and A. Heston, 1988, "A New Set of International Comparisons of Real Product and Price Levels: Estimates for 130 Countries, 1950-85", Review of Income and Wealth, Vol 17, pp. 239263.

Thoumi, 1989, "Trade Flows and Economic Integration Among LDCs of the Caribbean Basin," Social and Economic Studies, v. 38, \#2, pp. 215-233.

White, H., 1981, "Consequences and Detection of Misspecified Non-Linear Regression Models, " Journal of the American Statistical Association, v. 76, pp. 419-433.

Yeats, A., 1990a, "On the Accuracy of Economic Observations: Do Sub-Saharan Trade Statistics Mean Anything?," World Bank Economic Review, v. 4, pp. 135-156.

Yeats, A., 1990b, "Do African Countries Pay More for Imports? Yes." World Bank Economic Review, v. 4 , pp. $1-20$. 


\section{Pollcy Research Working Paper Serles}

Title

WPS1208 Primary School Achievement in English and Mathematics in Zimbabwe: A Mutti-Level Analysis

WPS1209 Should East Asia Go Rogional? No, No, and Maybe

WPS1210 The Taxation of Natural Resources: Principles and Policy issues

WPS1211 Savings-Investment Correlations Nlandu Mamingi and Capital Mobility in Developing Countries

WPS1212 The Links between Economic Policy Ravi Kanbur and Research: Three Examples from Ghana and Some General Thoughts

WPS1213 Japanese Foreign Direct Investment: Rocent Trends, Determinants, and Prospects

WPS1214 Trade, Aid, and Investment in Sub- Ishra! Husain Saharan Africa

WPS1215 How Much Do Distortions Affect Grown?

Commitment. Privatization and

Regulation in the Argentine

Telecommunications Sector

WPS1217 Unitary versus Collective Models of the Household: Time to Shift the Burden of Proot?

WPS1218 implementation of Trade Reform in Sub-Saharan Africa: How Much Heat and How Much Light?

WPS1219 Decentializing Water Resource Managyment: Economic Iricentives, Accountability, and Assurance

WPS1220 Developing Countries and the Uruguay Round: Negotiations on Services
Frank Flatters

Kwang W. Jun Frank Sader Haruo Horaguchi Hyuntai Kwak

Witliam Easterly

Alice Hill

Manuel Angel Abdala

\section{Date}

October 1993

\section{Contact}

for paper

I. Conachy

33669

October 1993

D. Ballantyne

37947

October 1993

C. Jones

37699

October 1993

R. Vo

31047

Octcber 1993

P. Attipoo 526-3003

November 1993

S. King-Watson 33730

November 1993

M. Youssef 34637

November 1993

R. Martin 39065

November 1993

D. Evans 38526

Pierre-Andre Chiappori

November 1993

P. Attipoe

526.3002

Lawrence Haddad

John Hoddinot

Ravi Kanbur

John Nash

November 1993

D. Ballantyne 37947

K. William Easter

Robert R. Hearne

Bernard Hoekman
November 1993
M. Wu 30480
L. OConnor 37009 


\section{Pollcy Research Working Paper Serles}

Title

WPS1221 Does Research and Development Contribute to Economic Growth in Developing Countries?

WPS1222 Trade Reform in Ten Sub-Saharan Countries: Achievements and Failures

WPS1223 How Robust is a Poverty Profile?

WPS1224 Devaluation in Low-Inflation Economies

WPS1225 Intra-Sub-Saharan African Trade: Is It Too Little?
Author

Nancy Birdsall

Changyong Rhee

Faezeh Foroutan

Martin Ravallion Benu Bidani

Miguel A. Kiguel Nita Ghei

Faezen Foroutan

Lant Pritchett
Date

Contact for paper

November 1993

S. Rajan 33747

November 1993

S. Fallon 38009

November 1993

P. Cook 33902

November 1993

R. Luz 39059

November 1993 S. Fallon 38009 